\title{
AGE-RELATED MORPHO-FUNCTIONAL CHANGES IN RATS' PANCREAS UNDER HIGH-FAT DIET-INDUCED INSULIN RESISTANCE AND ITS PHARMACOLOGICAL TREATMENT
}

D0l:10.36740/WLek202102112

\author{
Tatiana Yu. Kvitnitskaya-Ryzhova' ${ }^{1}$, Halyna V. Kosiakova'2 , Sergiy P. Lugovskoy ${ }^{1,3}$, Sergiy A. Mykhalskiy ${ }^{1}$, \\ Pavlo P. Klymenko', Svetlana P. Malysheva' ${ }^{1}, 0$ ksana S. Tkachenko ${ }^{2}$ \\ 'CHEBOTAREV INSTITUTE OF GERONTOLOGY NAMS OF UKRAINE, KYIV, UKRAINE \\ 2PALLADIN INSTITUTE OF BIOCHEMISTRY NAS OF UKRAINE, KYIV, UKRAINE \\ 'STATE INSTITUTION KUNDIIEV INSTITUTE OF OCCUPATIONAL HEALTH OF NAMS OF UKRAINE, KYIV, UKRAINE
}

\begin{abstract}
The aim: To determine the set of structural and functional changes in pancreatic islets (PI) of obesity-induced insulin resistant (IR) rats of different age (young and old) fed with prolonged (6 month) high-fat diet (HFD) (58\% of fat) and further treatment with N-Stearoylethanolamine (NSE), a bioactive N-Acylethanolamine.

Materials and methods: Alimentary obesity-induced IR model in rats of two age groups was used to investigate the influence of age and NSE treatment on pancreas morphology (using histological, histochemical and immunohistochemical techniques) and on several biochemical parameters associated with DM onset.

Results: The NSE administration normalized pancreas morphology which was more affected in the old IR group; the signs of inflammation, edema, fibrosis and steatosis were somehow diminished and PI area became significantly increased. The amount of the A-F-positive insulocytes increased and TUNEL-positive - decreased. Compensatory hyperplasia in the affected pancreas of both age was an important indicator of NSE stimulating effect.

Conclusions: Protective effects of NSE on morpho-functional state of pancreas in HFD-induced IR rats of both age are associated not only with its anti-inflammatory, anti-oxidant and anti-dyslipidemic properties but also with activation of PI hyperplasia and $\beta$-cells compensatory mechanisms.
\end{abstract}

KEY WORDS: experimental insulin resistance, pancreatic islets, Apoptosis, aging, N-Stearoylethanolamine

Wiad Lek. 2021;74(2):241-246

\section{INTRODUCTION}

Obesity-induced insulin resistance (IR) is tightly associated with type 2 diabetes mellitus (DM), one of the most severe world-spread multifactorial age-dependent metabolic diseases, accompanied by numerous complications. According to the International Diabetes Federation, as of 2015, there were 415 million patients on the planet, and as to forecasts for 2040 the number of people with DM will increase to 642 million, acquiring the scale of the "non-infectious" epidemic of the $21^{\text {st }}$ century $[1,2]$. Nowadays, there has been recorded an obvious aging of the population - an increase in the number of people over 60 throughout the world. Significant prevalence of DM, as well as IR and obesity, in particular is characteristic of such age category, which makes this pathology one of the main objects of gerontological research.

With continuing efforts to explore the structural basis for diabetes onset, progressive decline of $\beta$-cells of Langerhans pancreatic islets (PI) is established as a salient feature of type $2 \mathrm{DM}[3]$. That is why the mechanisms of cell failure and death, associated with the pathogenesis of this disease, are of great imp33ortance in the study of diabetes pathophysiology in different age [4-8]. Based on molecular biological studies, $\beta$-cells death in diabetic animal models has been attributed to oxidative stress and endoplasmic reticulum (ER) stress, as well as autophagy deficits [3, 9]. Thus, it is conceivable that oxidative stress damage has the strongest impact on these cells failure [10]. Pancreatic $\beta$-cell loss by apoptosis appears to play a crucial role in the development of insulin deficiency and the onset of CD [5]. Thus its age-dependent peculiarities should be taken into account for evaluation of the disease severity, prognosis and the effectiveness of various therapeutic approaches.

Evidently, $\beta$-cells are found to be more plastic, than previously thought, pointing towards the existence of powerful survival pathways. Their potentials for transdifferentiation and reversibility should be vigorously elucidated and could be a target of the future diabetes treatment $[3,6$, 11]. In a large number of studies devoted to the search for DM correction methods, there are numerous researches in the field of the therapy with minor lipids that belong to the $\mathrm{N}$-Acylethanolamines family and mediate a wide range of biological and pathological processes by interacting with cannabinoid and noncannabinoid receptors $[12,13]$. Recent studies indicate that $\mathrm{N}$-Stearoylethanolamine (NSE), a bioactive $N$-Acylethanolamine, has the membrane-stabilizing, 
anti-inflammatory anti-oxidant and anti-dyslipidemic action. It is able to regulate lipid metabolism, to improve the fatty acid imbalance and normalize the phospholipid levels. Such NSE-induced changes were associated with a normalization of plasma triglyceride content, considerable decrease of insulin and index HOMA-IR level in rats under IR conditions [12].

All this determines the need to investigate morpho-functional background of PI in the modeling of obesity-induced IR and its correction with NSE, taking into account the age-dependent features of these processes.

\section{THE AIM}

The purpose of the research - to study the structural, functional and morphometric features, as well as the intensity of apoptosis, in pancreatic islets of obesity-induced insulin resistant rats of different age (young and old) fed with prolonged (6 month) high-fat diet (HFD) (58\% of fat) and further treatment with $\mathrm{N}$-Stearoylethanolamine (NSE), a bioactive $\mathrm{N}$-acylethanolamine.

\section{MATERIALS AND METHODS}

Animal Model and Treatment. The study was carried out on male Sprague-Dawley rats of two age groups - young ( 4 mo at the beginning and $10 \mathrm{mo}$ at the end of the experiment) and old (16 and $22 \mathrm{mo}$, respectively). All the experiments were carried out according to the existing bioethical norms of the "European Convention for the Protection of Vertebrate Animals used for Experimental and other Scientific Purposes" (Strasbourg, 1986), as well as article 26 of the Law of Ukraine "On the Protection of Animals against Cruelty" (No. 3447-IV, 21.02.2006). Rats were housed in standard cages with free access to food and water.

Obesity-induced IR was attained by feeding a prolonged HFD ( $58 \%$ fat: $23 \%$ proteins: $10 \%$ carbohydrates for 6 months) as described earlier [12]. The amount of lipids in the diet was increased by adding of lard to the pellet diet, which contained a high level of palmitic ( $24 \%$ of total fatty acids (FA)) and stearic (28\% of total acids) acids. The HFD-FA composition was at a ratio of $55 \%$ saturated (SFA) to $45 \%$ unsaturated FA (USFA). Control rats were on normal pellet diet ( $4 \%$ fat:23 \% proteins: $65 \%$ carbohydrates) with SFA/USFA ratio $38 \% / 62 \%$, respectively.

Six months after HFD period, we conducted the oral glucose tolerance test $[12,13]$. The rats of each age group (young and old) with impaired glucose tolerance (the level of blood glucose within $150 \mathrm{~min}$ after the oral glucose administration was higher than $5 \mathrm{mmol} / \mathrm{l}$ ) were selected and divided randomly into two groups: IR (young $-\mathrm{n}=16$; old $-\mathrm{n}=12$ ) and IR + NSE (young $-\mathrm{n}=15$; old $-\mathrm{n}=12$ ). Control rats were further subdivided into control (young $-\mathrm{n}=4$; old $-\mathrm{n}=3$ ) and NSE (young $-\mathrm{n}=3$; old $-\mathrm{n}=3$ ) groups. Animals in NSE and IR + NSE groups received the water suspension of NSE at the dose of $50 \mathrm{mg}$ body weight $\mathrm{kg}^{-1}$ per os for 2 weeks. This particular dose of NSE has been chosen as an optimal reacting dose for the biological effect investigations $[12,13]$. At the end of the experiments, the rats were decapitated under Nembutal anesthesia (50 $\mathrm{mg} / \mathrm{kg}$ body weight).

Biochemical Analysis. Blood glucose levels were controlled using glucometer Rightest GM-110 (Bionime $\mathrm{GmbH}$, Switzerland). The establishment of IR was confirmed based on the results of fasting plasma insulin levels (measured by Rat Insulin ELISA kit, Thermo Fisher Scientific, USA) and HOMA-IR (homeostatic model assessment - insulin resistance) value [calculated by fasting insulin $(\mu \mathrm{IU} / \mathrm{mL}) \times$ fasting glucose $(\mathrm{mmol} / \mathrm{L}) / 22.5]$.

Histological Examination. The pancreas was immediately removed and fixed in Bouin's solution. After dehydration the tissue samples were processed for the embedding in Paraplast ${ }^{\circ}$ (type 6, Richard-Allan Scientific, USA). Serial sections $(5 \mu \mathrm{m})$ were cut on a rotation microtome HM 325 (Microm, Germany) and then stained with hematoxylin and eosin (H \& E) and Gomori's Aldehyde-Fuchsin (A-F) for detection of secretory granules in $\beta$-cells. The obtained histological specimens were studied and photographed at $\mathrm{x} 40, \mathrm{x} 100, \mathrm{x} 200$ and $\mathrm{x} 400$ magnification using a BX51 microscope and DP-Soft 3.2 software (Olympus, Japan). In all studied groups of experimental animals (control, IR, IR+NSE in two ages) the following morphometric parameters were estimated: the area of PI, their number per $1 \mathrm{~mm}^{2}$ of the pancreas sections, the specific volume of endocrine tissue in the total volume of pancreas; specific volume of A-F-positive $\beta$-cells in the total volume of PI.

TUNEL-staining. Apoptosis was detected using TUNEL assay with ApopTag ${ }^{\oplus}$ Plus Peroxidase In Situ Apoptosis Detection Kit (Chemicon, USA). TUNEL staining was performed according to the protocol provided with the kit. The apoptotic index (AI) was calculated as the number of TUNEL-positive cells per $1 \mathrm{~mm}^{2}$ of the PI section area.

Statistical Analysis. Statistical processing of the morphometric study data was performed using the Statistica 13 and GraphPad Prism 8 programs. Variational raws of data were preliminary checked to fit normal distribution, using for this purpose analysis of frequencies, and Lilliefors and Shapiro-Wilk test criteria. The obtained data were presented as mean value (M) and its standard error (SE), as well as minimal and maximal values, median $(\mathrm{Me})$ and $95 \%$ of the confidence interval [95\% CI]. Estimation of the statistic hypotheses during comparison of two independent groups was performed using Mann Whitney $\mathrm{U}$ and Kolmogorov-Smirnov criteria at $\alpha=0.05$.

\section{RESULTS}

\section{BIOCHEMICAL AND PHYSIOLOGICAL RESULTS}

Throughout the experiments, the rats were gaining weight gradually. On the $24^{\text {th }}$ week, the average weight of HFD rats was higher (due to visceral fat) in comparison with control rats. The obesity was more prominent in the old IR rats compared to the young that reflects the age differences in the rate of their metabolism. There was an elevation in fast- 
Table I. Body weight and several biochemical parameters in the control and treated rat groups $(\mathrm{M} \pm \mathrm{SE})$

\begin{tabular}{|c|c|c|c|c|c|c|c|c|}
\hline \multirow[b]{2}{*}{ Parameter } & \multicolumn{4}{|c|}{ Young } & \multicolumn{4}{|c|}{ Old } \\
\hline & Control & C+NSE & IR & IR+NSE & Control & C+NSE & IR & IR+NSE \\
\hline Body weight (g) & $\begin{array}{c}479.0 \pm \\
24.91\end{array}$ & $\begin{array}{c}506.33 \pm \\
36.29\end{array}$ & $\begin{array}{c}500.0 \pm \\
11.50\end{array}$ & $\begin{array}{c}509.81 \pm \\
16.74\end{array}$ & $\begin{array}{c}480.20 \pm \\
19.21\end{array}$ & $\begin{array}{c}489.33 \pm \\
15.40\end{array}$ & $\begin{array}{c}577.0 \pm \\
38.29\end{array}$ & $\begin{array}{c}611.2 \pm \\
29.58\end{array}$ \\
\hline $\begin{array}{l}\text { Blood glucose } \\
(\mathrm{mmol} / \mathrm{L})\end{array}$ & $\begin{array}{c}3.70 \pm \\
0.19\end{array}$ & $\begin{array}{c}3.73 \pm \\
0.09\end{array}$ & $\begin{array}{c}5.94 \pm \\
0.24\end{array}$ & $\begin{array}{c}4.93 \pm \\
0.09\end{array}$ & $\begin{array}{c}4.63 \pm \\
0.32\end{array}$ & $\begin{array}{c}4.90 \pm \\
0.42\end{array}$ & $\begin{array}{c}5.93 \pm \\
0.19\end{array}$ & $\begin{array}{c}5.39 \pm \\
0.34\end{array}$ \\
\hline $\begin{array}{l}\text { Serum insulin } \\
(\mu \mathrm{lU} / \mathrm{mL})\end{array}$ & $\begin{array}{c}0.57 \pm \\
0.04\end{array}$ & $\begin{array}{c}1.46 \pm \\
0.08\end{array}$ & $\begin{array}{c}2.45 \pm \\
0.60\end{array}$ & $\begin{array}{l}1.97 \pm \\
0.35\end{array}$ & $\begin{array}{c}2.86 \pm \\
0.93\end{array}$ & $\begin{array}{c}3.45 \pm \\
0.08\end{array}$ & $\begin{array}{c}4.24 \pm \\
1.43\end{array}$ & $\begin{array}{c}2.47 \pm \\
0.45\end{array}$ \\
\hline HOMA & 0.09 & 0.24 & 0.65 & 0.43 & 0.59 & 0.75 & 1.12 & 0.59 \\
\hline
\end{tabular}

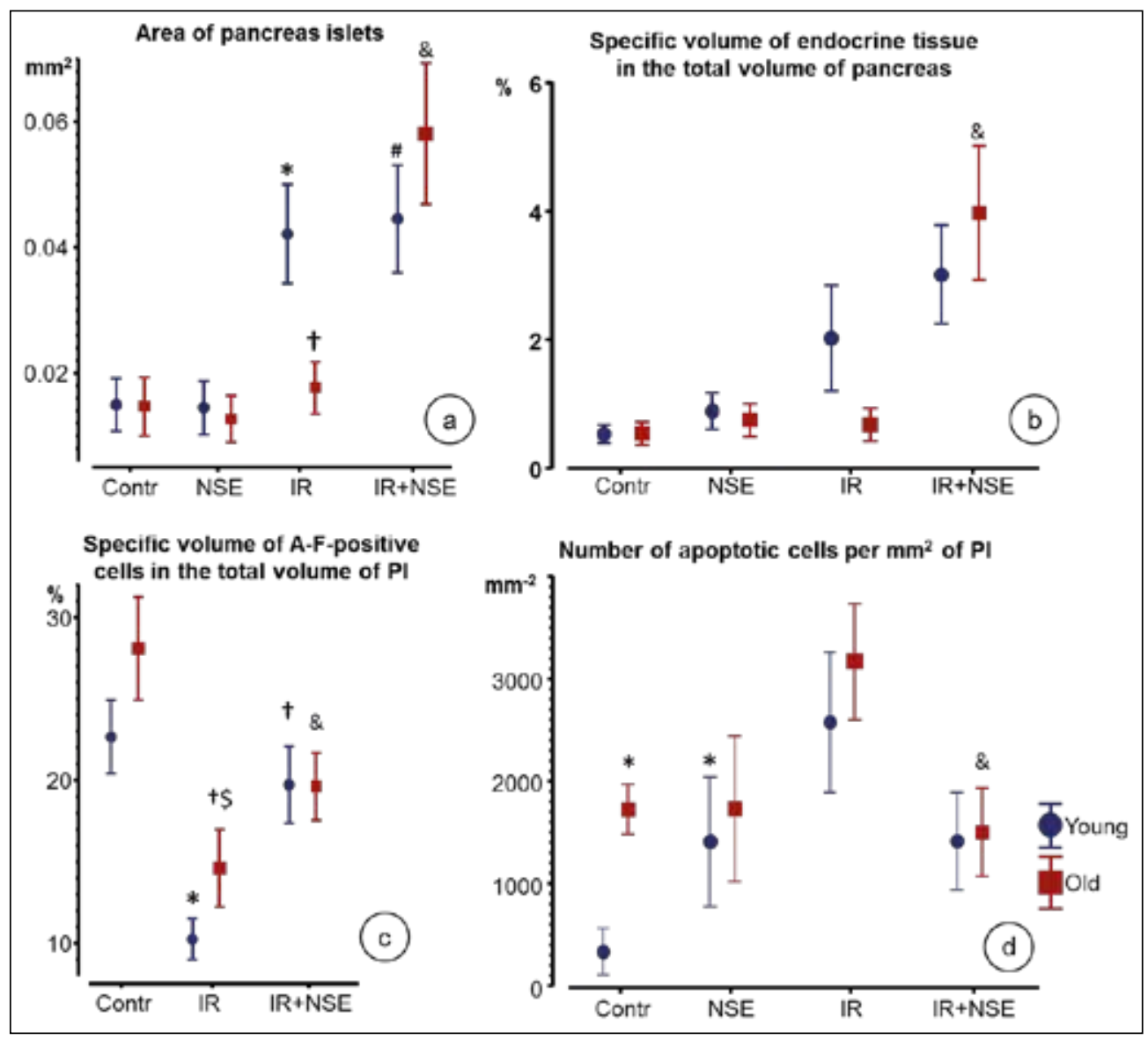

Fig 1. Pl area (a), specific volume of endocrine tissue in the total volume of pancreas (b), specific volume of A-Fpositive cells in the total volume of $\mathrm{PI}$ (c), number of TUNEL-positive cells per $\mathrm{mm} 2$ of PI (d) of young and old rats of various experimental groups (Control, NSE, IR, IR+NSE); mean with $95 \%$ (I on a), c), d), mean with SE on b); $P<0.05:^{*}$ - vs C-young, \#-vs C-y+NSE, $\dagger-$ vs IR-young, \$ - vs C-old, \& - vs IR-old. ing blood glucose and serum insulin in HFD rats of both age. NSE treatment somehow normalized these values - in the young rats to a greater extent than in the old (Table 1).

\section{HISTOLOGICAL FINDINGS}

Morphological examination of the control animals' pancreata revealed its typical architecture in both age groups. Endocrine cells formed aggregates (islets) of various sizes and shape, more often small, ellipsoid or spherical. The PI epithelial cells were separated by a network of anastomosing capillaries. The morphometric parameters (the PI area and the specific volume of PI in the total volume of the pancreatic tissue) did not display significant age-related differences (Fig.1 a, b). However, in the old control some dystrophic changes of insulocytes, small accumulations of macrophages in peripheral connective tissue, as well as islet vessel dilatation, were demonstrated.

The number of insulocytes with A-F-positive secretory granules in the cytoplasm (the indicator of PI functional activity) differed a little in the young and old control animals, although its spread was significantly larger in the old, which reflects the heterogeneity of the morphological features that is generally characteristic of aging (Fig. 1 c).

Obesity-induced IR rats demonstrated severely disorganized PI architecture in both age groups. The contour of the islets and their shape became irregular (Fig. 2a). PI appeared to be larger in size and quantitatively more numerous compared with normal-diet controls in the young group whereas these values didn't change significantly in the old animals (Fig.1 a, b). At the same time the number of insulocytes with structural disarrangements and dys- 


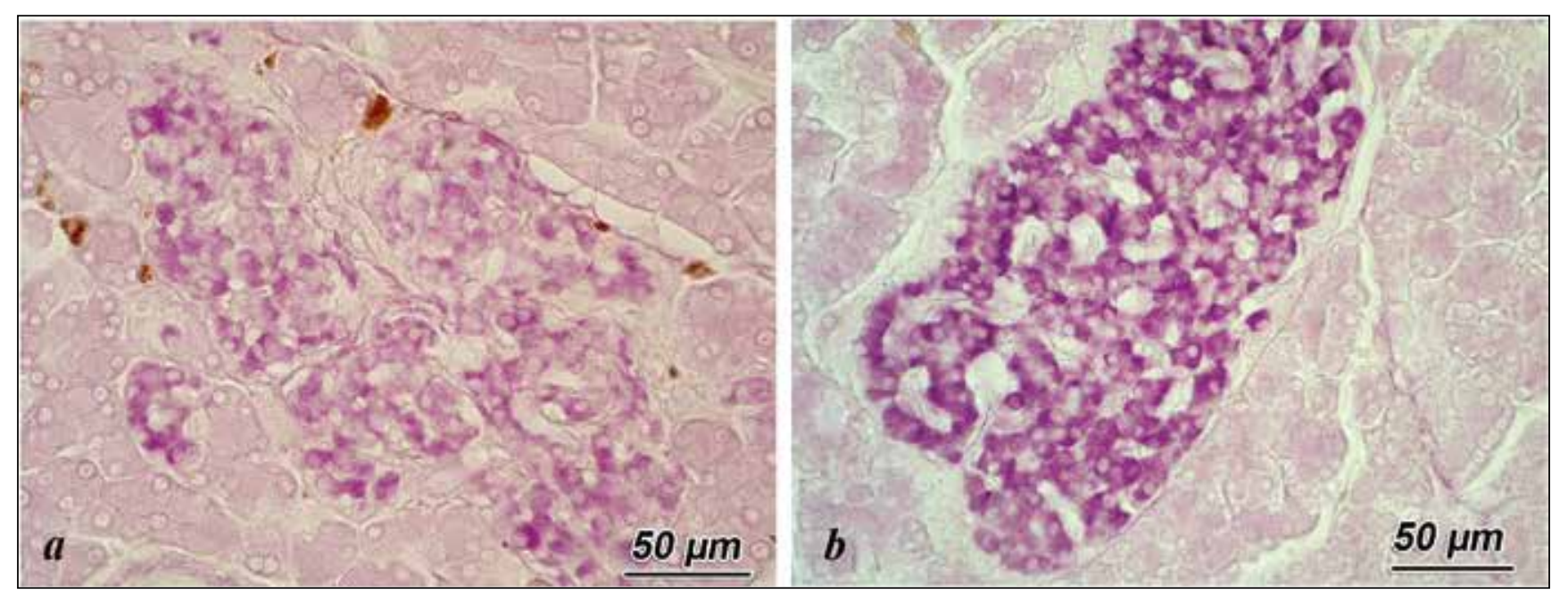

Fig 2. Pl of young IR (a) and IP+NSE (b) rats with low and high histochemical activity of insulocytes (Aldehyde-Fuchsin staining).

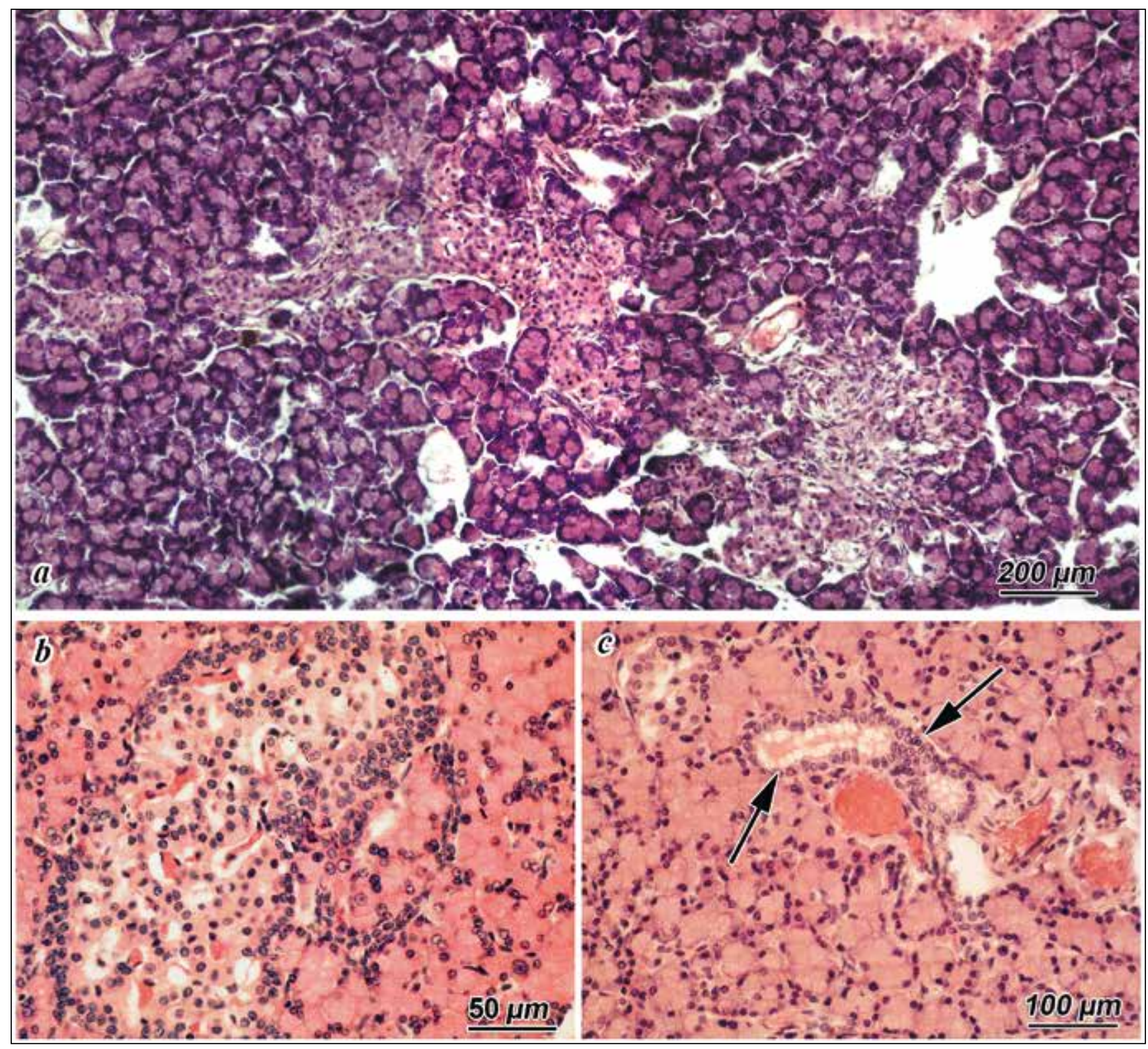

Fig 3. Pancreatic sections of old (a) and young ( $b, c)$ rats of IR+NSE groups. Irregular shape and hyperplasia of PI (a). Hyperplasia of PI cells (b) and duct epithelium (arrows) (c). (H\&E). 
trophic changes, as well as edema of their cytoplasm, was much higher in the old IR rats compared to young. The damaged islets were also more numerous in the old age group. Pronounced islet vessel dilatation was observed as well (Fig. 2 a). Moreover, the presence of inflammatory infiltration as well as fibrosis were found in PI of the predominantly old animals. Besides it was possible to observe fatty replacement of the exocrine pancreas in both age groups (more pronounced in the old) which is the manifestation of pancreas steatosis in long-term HFD treated animals.

While inducing IR, the level of functional activity of the insulocytes decreased sharply in the rats of both age, reflecting the deeper destructive, dystrophic and atrophic processes in the PI of obesity-induced IR animals. The A-F-positive area in affected pancreas was significantly smaller than in normal conditions (Fig. $1 \mathrm{c}$ ). There were insulocytes that had very few secretory A-F-positive granules in their cytoplasm that corresponds to reduced number of the functionally active $\beta$-cells that is resulting in decrease of insulin secretion (Fig. 2 a).

Obesity-induced IR rats treated with NSE showed pronounced changes of PI architecture in both age groups. Though their morphology was normalized to a certain extent, the quantitative parameters of PI changed evidently (Fig. $1 \mathrm{a}, \mathrm{b}$ ). Islet size was significantly increased in groups IR+NSE compared both to IR and control groups (Fig. 3 a). The islets became both enlarged and much more irregular in shape; sometimes they lost the oval-like shape and spread along the pancreas. Such PI enlargement was associated with islet cells hyperplasia that was observed not only in IR+NSE groups but also in control animals that received NSE (Fig.3 b). Moreover, there has been shown the hyperplasia and hypertrophy of duct wall epithelium which is considered to be primitive precursor cells and a primordium of islets (Fig. $3 \mathrm{c}$ ). The level of inflammatory infiltration was reduced in PI of IR+NSE young animals more then in old ones and the islet vessel dilatation was also a little bit declined in these groups.

In IR+NSE groups the amount of insulocytes with A-F-positive secretory granules in their cytoplasm increased compared to HFD treated animals that did not receive NSE, though these parameters did not gain the control values (Fig.1 c, 2 b).

\section{TUNEL IMMUNOHISTOCHEMISTRY}

Apoptotic cells were detected by TUNEL assay and appeared as brown-stained. The level of apoptosis in PI was significantly higher in old control animals compared to young due to age-related changes in the gland (Fig. $1 \mathrm{~d}$ ).

While inducing IR, AI in PI increased significantly, especially in the old rats, being correlated with much deeper structural damage of the pancreas, that was noted in this age group. The IR+NSE groups showed a decrease of AI in PI compared to the animals that did not receive NSE treatment (Fig.1 d). That is an objective criterion for the effectiveness of this kind of therapy.

\section{DISCUSSION}

The age aspect of the CD pathomorphosis acquires special attention not only due to an obvious increase in the prevalence of this pathology with age, but also because a number of its manifestations, in terms of their morphological characteristics, resemble the age changes typical for normal physiological aging. Evidently, the pre-existing age-related morphological and functional alterations in various organs contribute to the development of deeper diabetic lesions, which has been confirmed by our previous data $[7,8]$. Our study of the corrective effects of gene therapy (with PEI-pDNA complex containing the human preproinsulin gene) on the morphological and functional characteristics of various mice organs, including pancreas, at streptozotocin-induced DM showed its different efficacy in different age: high effectiveness in the young animals and a slight effect, its absence, or even additional deteriorations (e.g. insulitis) in the old ones. So the effects of gene therapy application in this mice model appeared to be age-dependent.

In this study, performed on the rat model of HFD-induced obesity, IR and subsequent type 2 diabetes, we did not determine demonstrative and pronounced age-related differences in the effectiveness of NSE treatment which is considered to be a novel anti-diabetic drug $[12,13]$. Thus, pharmacological treatment with NSE of obesity-induced IR rats appeared to be rather effective in both ages despite of definite age-related distinctions in their reaction to the long-term HFD treatment, as has been shown in this study.

The NSE administration normalized to a certain degree pancreas morphology which was more affected in the old IR group; the signs of inflammation, edema, fibrosis and steatosis were somehow diminished. The amount of the A-F-positive insulocytes increased and TUNEL-positive - decreased. In addition, the NSE treatment stimulated the development of compensatory hyperplasia in the affected pancreas, which is an important indicator of its protective effects on the IR animals' pancreas of both age, supporting the role for divergent mechanisms in controlling adaptation to metabolic demand.

Despite the existence of contradictory data, the viewpoints about the worsening of $\beta$-cells function in aging, the decrease in their proliferative activity and the increase in the apoptosis level prevail in the literature $[3,6]$. At the same time, numerous studies performed in animal models, as well as in patients with DM, associated with the study of the mechanisms of injury, death, regeneration and adaptation of $\beta$-cells, indicate that they have greater plasticity than previously thought, which allows to consider them to be a perspective target for finding new ways for DM treatment $[3,6,11]$. The potential mechanisms of $\beta$-cell regeneration, including their self-replication, neogenesis from non- $\beta$-cell precursors and transdifferentiation from a-cells, as well as tissue stem cells, are discussed by the different authors [3, $14,15]$. The ability of the pancreas to regenerate mature $\beta$-cells is explored in pathological conditions, including diabetes and inflammatory injury.

Our findings of the pronounced PI compensatory hyperplasia as well as the duct epithelium activation after NSE 
administration both in the intact and in the HFD-induced IR rats of different age revealed the strong capacity for islets regeneration that is preserved even in the old. Such results concerning impressive plasticity of the endocrine pancreas of adult and even old animals under pharmacological activation are especially important, since they can help to clarify the characteristic features of corrective effects at this disease in old age.

\section{CONCLUSIONS}

Our data obtained by biochemical, histological, histochemical and immunohistochemical techniques confirmed the development of PI histopathological alterations in the obesity-induced IR rats of two age groups fed with prolonged (6 mo) HFD, which were more pronounced in the old animals. The NSE administration normalized pancreas morphology: the signs of inflammation, edema, fibrosis and steatosis were somehow diminished. The amount of the functionally active A-F-positive insulocytes increased and TUNEL-positive cells, involved in apoptosis process - decreased. This serves an objective criterion for the effectiveness of such kind of therapy.

Our findings of the pronounced PI compensatory hyperplasia as well as the duct epithelium activation after NSE administration both in the intact and in the HFD-induced IR rats of different age revealed the strong capacity for islets regeneration, enlargement and activation that is preserved even in the old animals.

The protective effect of NSE on morpho-functional state of pancreas in HFD-induced IR rats of different age can be associated not only with its anti-inflammatory, anti-oxidant and anti-dyslipidemic properties but also with its capacity to activate PI hyperplasia and $\beta$-cells compensatory mechanisms.

\section{REFERENCES}

1. World Health Organization Media Centre. Diabetes fact sheet. 2016. http://www.who.int/mediacentre....

2. International Diabetes Federation: Diabetes Atlas. 8th Ed. 2018. http:// www.diabetesatlas.org/i....

3. Yagihashi S., Inaba W., Mizukami H. Dynamic pathology of islet endocrine cells in type 2 diabetes: $\beta$-cells growth, death, regeneration and their clinical implications. J. Diabetes. Investig. 2016; 7(2):155-165.

4. Lee S.C., Pervaiz S. Apoptosis in the pathophysiology of diabetes mellitus. Int. J. Biochem. Cell. Biol. 2007; 39(3):497-504.

5. Lupi R., Del Prato S. $\beta$-cell apoptosis in type 2 diabetes: quantitative and functional consequences. Diabetes \& Metabolism. 2008; 34:56-64.

6. Coppieters K.T., von Herrath M.G. Histopathology of type 1 diabetes: old paradigms and new insights. Rev. Diabet. Stud. 2009; 6 (2):85-96.

7. Kvitnitskaya-Ryzhova T.Yu., Lugovskoy S.P., Klimenko P.P. et al. Izmeneniya struktury razlichnyh organov i vyrazhennosti apoptoza u myshey raznogo vozrasta pri modelirovanii sakharnogo diabeta i ego korrektsii [Age-related changes of various organs and apoptosis intensity in mice of different age at modeling of experimental diabetes mellitus and its correction]. Problems of aging and longevity. 2017; 26(3-4):184206. (in Russian).
8. Kvitnitskaya-Ryzhova T.Yu, Lugovskoy S.P., Klymenko P.P. et al. The effects of gene therapy with PEI-pDNA complex containing human preproinsulin gene on structural and ultrastructural characteristics of several organs in mice of different age at experimental diabetes mellitus. Cell and organ Transplantology. 2018;6(1):48-56.

9. Watada H., Fujitani Y. Minireview: Autophagy in pancreatic $\beta$-cells and its implication in diabetes. Mol. Endocrinol.2014;29 (3):338-348.

10. Mizukami H., Takahashi K., Inaba W. et al. Involvement of oxidative stress-induced DNA damage, endoplasmic reticulum stress and autophagy deficits in the decline of $\beta$-cell mass in Japanese type 2 diabetic patients. Diabetes Care. 2014; 37 (7):1966-1974.

11. Brereton M.F., Iberl M., Shimomura K., et al. Reversible changes in pancreatic islet structure and function produced by elevated blood glucose. Nature Communications.2014;5:4639. doi:10.1038/ ncomms 5639

12. Onopchenko A.V., Kosiakova G.V., Oz M. et al. N-Stearoylethanolamine restores pancreas lipid composition in obesity-induced insulin resistant rats. Lipids. 2015; 50(1):13-21.

13. Berdyshev A.G., Kosiakova G.V, Onopchenko A.V. et al. $\mathrm{N}$-Stearoylethanolamine suppresses the pro-inflammatory cytokines production by inhibition of NF-kB translocation. Prostaglandins \& Other Lipid Mediat. 2015;121(part A):91-96.

14. Li M., Ikehara S. Bone marrow stem cell as a potential treatment for diabetes. J. Diabetes. Res. 2013. doi: 10.1155/2013/329596.

15. Wu J., Yang X., Chen B. et al. Pancreas $\beta$-cell regeneration and type 1 diabetes (review). Exp. Ther. Med. 2015; 9; 653-657. doi: 10.3892/ etm.2014.2163.

\section{ORCID and contributionship:}

Tatiana Yu. Kvitnitskaya-Ryzhova: 0000-0002-8746-5024 Halyna V. Kosiakova: 0000-0002-1214-2044 A,E

Sergiy P. Lugovskoy: 0000-0002-3948-7026 $6^{B, C}$

Sergiy A. Mykhalskiy: 0000-0002-7232-4608 ${ }^{B, C}$

Pavlo P. Klymenko: 0000-0001-9905-1956 ${ }^{B}$

Svetlana P. Malysheva: 0000-0001-9440-6359 ${ }^{B}$

Oksana S. Tkachenko: 0000-0001-5497-6533 ${ }^{B}$

\section{Conflict of interest:}

The Authors declare no conflict of interest.

\section{CORRESPONDING AUTHOR Tatiana Yu. Kvitnitskaya-Ryzhova}

Chebotarev Institute of Gerontology NAMS of Ukraine

67 Vyshgorodska, 04114 Kyiv, Ukraine

tel: +380948315869

e-mail:morphology@geront.kiev.ua

Received: 07.04 .2020

Accepted: 10.11 .2020

A - Work concept and design, B - Data collection and analysis, C - Responsibility for statistical analysis,

D-Writing the article, $\mathbf{E}$-Critical review, $\mathbf{F}$ - Final approval of the article 